\title{
EL PUERTO DE ALICANTE DURANTE LA BAJA EDAD MEDIA
}

\author{
José Hinojosa Montalvo \\ Universidad de Alicante
}

\section{EL PUERTO COMO ELEMENTO DINAMIZADOR DE LA CIUDAD}

Si hubiera que señalar dos símbolos característicos de Alicante a lo largo de su historia éstos serian el castillo y el puerto. Sobre la importancia militar estratégica del primero no hace falta insistir. Los monarcas aragoneses calificaron a la plaza, en virtud de su fortaleza, de «clau del nostre regne" y ello se demostró con diferente fórtuna en numerosas confrontaciones bélicas, particularmente las guerras con Castilla a mediados del siglo XIV. En cuanto al puerto, aparece indisolublemente unido a la vida económica de la ciudad desde la Antigüedad, siendo su elemento más dinámico, auténtico barómetro de su trayectoria histórica, tal como ha puesto de relieve recientemente Enrique Giménez para el siglo XVIII (1). Podría trasladarse aquí el título de la famosa obra de Ramón Carande sobre Sevilla y acuñar la frase «Alicante, fortaleza y mercado».

Paradójicamente es muy poco lo que se sabe del puerto de Alicante en la Edad Media: apenas unas cuantas menciones en los privilegios de Alfonso $X$ el Sabio y un par de trabajos de Martínez Morellá (2) y el más reciente de Torres Fontes (3). Este último autor pone de relieve la importancia del puerto de Alicante bajo la dominación castellana, entre 1243 y 1296, como puerta de Castilla al mar junto con Cartagena. El Rey Sabio benefició a los vecinos de la villa con numerosos privilegios, entre ellos la exención del impuesto del ancoraje a cuantos mercaderes vinieren a Alicante (1257) (4). El puerto y la ciudad sirvieron también como base de apoyo logístico y naval para la recuperación del territorio mu rciano tras la sublevación mudéjar de 1264 y posteriores campañas de Jaime I (5). 
El deseo de Alfonso $X$ de repoblar la villa de Alicante e impulsar su desarrollo mercantil se refleja en el privilegio de 2 de mayo de 1271 ordenando que todos los pasajes hacia Ultramar se hicieran por los puertos de Alicante y Cartagena, y en el intenso comercio de finales del siglo XIII en el que participaban cristianos, moros y judíos, que traficaban con toda clase de alimentos y materias primas: aceite, higos, pasas y frutos secos, especias, trigo, harina, cuerdas, esparto, etc. Es una etapa de crecimiento (6).

Ya no volvemos a tener noticias del puerto de Alicante hasta la segunda mitad del siglo XIV. De lo que no cabe duda es de la quiebra en la prosperidad que se produjo a mediados de la centuria. No sabemos cuál fue el grado de incidencia de la peste negra y otras calamidades naturales en la villa, pero sí que las guerras entre Castilla y Aragón se cebaron duramente sobre esta plaza hasta el punto de producir su ruina y despoblación (7).

Con la paz vino la recuperación. Pedro IV quiso reanimar el comercio y fundó la Lonja de Contratación en 1370 (8). En 1389, Juan II, a súplicas de las autoridades locales, ordenó que se respetara el privilegio dado por Alfonso $X$ declarando francos «d'ancoratge o d'estaca» a los barcos que llegaran a puerto, cortando asi las pretensiones de algunos particulares que en base a ciertas concesiones de Pedro IV reclamaban este derecho, en perjuicio de la villa, ya que muchas embarcaciones no venían "volents esquivar lo dit ancoratge» (9).

En 1433 el infante don Juan, lugarteniente del reino, ante las noticias de que muchos vecinos de Alicante sacaban mercancías, entre ellas "coses vedades», por algunos puertos apartados y sin vigilancia, como el Cap del Aljup, con daño para las regalias de la villa, ordenaba que nadie cargara en estos puertos y en especial del citado del Cap del Aljup, salvo los vecinos de Elche y Crevillente, que ya lo hacian tradicionalmente, canalizándose todas las exportaciones por el "port e carregador» de Alicante (10).

El puerto de Alicante siguió creciendo y a finales del siglo XV se había convertido en el segundo del pais, tras el de Valencia. De su actividad nos dejó una breve pero interesante descripción el viajero alemán Jerónimo Münzer, que el 11 de octubre de 1494 decía, entre otras cosas: "En la parte oriental de esta tierra elabórase mucha cantidad de vino blanco, pero es más aún del que llaman tinto de Alicante, de gran mercado en Inglaterra. Escocia, Flandes y otros lugares de Europa... El día que paramos en la ciudad vimos en el puerto 26 naves de Vizcaya, de Flandes y de otros paises que iban por cargamento de vino" (11).

¿Cómo era el puerto de Alicante en la Edad Media? Las instalaciones debian ser muy simples, un muelle o cargador («moll o carregador») para atraque de las embarcaciones, complementado con almacenes para depósito de mercancías e instalaciones defensivas. Julia López Gómez señala, citando a Viravens, que el muelle se prolongaba en el mar 200 
pasos, aunque no dice la fecha de la noticia (12). En 1491 se pagaron a mosén Joan Francesch 47 libras, 5 sueldos y 8 dineros por el gasto de dos bombardas gruesas que se trajeron de Vizcaya para defender el muelle (13), y todos los años en los gastos se incluye alguna partida para la compra de pólvora para aquéllas. Funcionarios del muelle eran un clavario, un escribano y un corredor.

\section{EL COMERCIO DE EXPORTACION}

Las fuentes básicas para conocer este comercio son las cuentas de la bailia de Orihuela, Alicante, en la sección del Maestre Racional del Archivo del Reino de Valencia, conservadas desde 1376 en adelante, aunque con alguna laguna a fines del siglo XIV (14); un par de libros de la colecta del "dret del general» de fines del siglo XV, en los fondos de Generalitat del mismo archivo (15), y un libro sobre el «dret del moll», en el Archivo Municipal de Alicante (16). Fuentes incompletas por cuanto, además de su fragmentación temporal, sólo nos muestran aspectos parciales del comercio de exportación marítimo por el puerto de Alicante. No obstante trataremos de reconstruir sus lineas generales.

\section{a) Mercaderes y patrones}

El elemento fundamental en los intercambios comerciales es el hombre, el factor humano, representado por los mercaderes y los patrones de embarcaciones. En el caso de los mercaderes, en muy pocas ocasiones se indica su procedencia, aunque los apellidos pueden servirnos como pista para identificar aquélla. Entre los peninsulares los más activos serian los de la propia Alicante, entre los que destacan por su repetición en 1468 y 1490 individuos como Pere, Joan y Jacme Dartes, Joan y Antoni Frances, Antoni y Bernat Mingot, Perot Burgunyo, Joan y Bernat Quexans, o el mismo baile de la villa Alfonso Martínez de Vera, que a menudo traficaba con esclavos; la repetición de algunos apellidos hace pensar en negocios de tipo familiar.

Del resto de la Corona de Aragón, habría que citar a valencianos, mallorquines y catalanes. De los primeros merece citarse el mercader converso de Valencia, Lluis Vives, que en 1490 cargó en la nave de Moroncho 40 cajas de azúcar y 2 de azúcar candí por valor de 450 libras; 9 cajas de almendras por 50 libras; 7 cargas de arroz por 14 libras; 2 cargas de rubia de primera calidad por 8 libras; 2 cortinas de raso de Tournai, que valian 60 libras. Este valioso cargamento se destinaba a Levante, pero la nave varió su itinerario hacia Poniente, por lo que hubo de trasvasar todas las mercancías a diversas embarcaciones (17). Los catalanes acudían a Alicante a comprar arroz, frutos secos, cochinilla, que cargaban en bu- 
ques catalanes o italianos para cambiarlos en Flandes por tejidos de calidad (18).

Muy numerosos eran los mercaderes castellanos en el Alicante bajomedieval, en particular andaluces (Sevilla, Sanlúcar, Marchena, Baeza...) y vascos, reconocibles éstos por sus apellidos (19).

Los extranjeros parece que no formaban una colonia muy consistente, y serían los italianos (genoveses, pisanos, florentinos y venecianos) los que más comerciaban con Alicante, si bien desde la segunda mitad del siglo XV se detecta la presencia de los alemanes a través de la Pequeña y la Gran Compañia, denominaciones que son indicativas del volumen de negocios de cada una de ellas (20). En 1468 joan Alamany, en nombre de la Gran Companya exportaba especias a Flandes en la nave de micer Jacobo Rinaldo (21) y el alemán Jous representaba en 1490 a la Pequeña Compañia, con envíos a Flandes y Levante.

Moros y judíos sólo aparecen ocasionalmente, comerciando sobre todo con Almería y Levante.

Profesionalmente no todos tienen el comercio como su principal actividad y muchos participaban en él ocasionalmente, desde el baile local hasta tenderos, tundidores, carreteros, etc. siendo habitual la presencia de miembros de las tripulaciones de las embarcaciones, que aprovechaban las escalas para llevarse algunas mercancias con las que luego negociar, redondeando así su salario; entre ellos se citan marineros, el escribano, despensero, contramaestre, guardián de la nave, alguacil, calafate o el mismo patrón.

\section{b) Tipos de embarcación}

Aunque no siempre, en ocasiones el escribano consignaba el tipo de embarcación que salía del puerto alicantino. A partir de aquí podemos obtener algunas conclusiones. La más importante es ver cómo este tráfico, que podemos calificar en gran parte de larga distancia, estaba monopolizado por naves y carabelas. Si en 1468 estas últimas superan a las naves, en 1490 la tendencia se invierte y las naves son las primeras. La nave (nau), de velas cuadradas, suele tener cuatro árboles y su porte superaba las cien toneladas, siendo sus destinos Levante, Flandes y puertos mediterráneos. La procedencia no se indicaba normalmente. La carabela, enormemente popularizada a finales deł Medievo por los descubrimientós geográficos, tenía un arqueo inferior a las cien toneladas, e incluso a las 25; de vela triangulares, a veces adopta las cuadradas; la utilizaban con preferencia andaluces y portugueses, viajando a menudo en flotillas. En 1468 la mayoria van a Flandes.

Las galeras, alternando la propulsión a remos y a velas, así como sus variantes la galeaza y la goleota son todas italianas y realizan la travesía Italia-Flandes. Otras embarcaciones son los laudes y balleneros, de porte 
más modesto, que se mueven fundamentalmente en aguas mediterráneas, lo mismo que saetas, leños y barcas, de escaso tonelaje pero muy aptas por su movilidad para el tráfico de cabotaje.

\section{c) Los destinos}

La primera distinción que se impone es la de paises maritimos e interiores. Tierra adentro, la práctica totalidad de los envíos se dirigen a Castilla (42 asientos en 1490), lo que ratifica el papel desempeñado por el puerto de Alicante como centro redistribuidor de mercancias foráneas hacia las regiones interiores de la Península. Otros centros castellanos importadores son las vecinas localidades de Murcia y Villena, hacia donde se enviaba queso y sardina. Aunque no detectadas, por el momento, cabe pensar en los cereales como el grueso de la exportación castellana hacia Alicante.

En el ámbito maritimo, la distribución principal se establece entre las cuencas mediterránea y atlántica. La del Mediterráneo es el nexo de las principales rutas que convergen en Alicante. Los contactos más intensos eran con las islas Baleares, en particular Mallorca ( 11 asientos en 1468 y 6 en 1490), seguida de lbiza. No hay que olvidar la excelente posición estratégica de las islas, y en muchos casos Mallorca era una de las escalas en la línea Alicante-Levante. Los aparejos elaborados con esparto y los frutos secos constituian el grueso del flete hacia las islas.

El comercio con Cataluña se canalizaba hacia los puertos de BarceIona, Tortosa y Tarragona, si bien en esta documentación aparece como de escaso relieve. Claude Carrere señala que en 1404 Barcelona importó mercancías de Alicante por valor de 1.428 libras, 15 sueldos, transportadas en 9 barcas (22).

En las costas provenzales aparece Niza con tres salidas en 1468, exportándose pasas y frutos secos y cubriendo este itinerario en dos ocasiones (15 de julio y 27 de octubre) la nave del vasco Martín de Oribari (23). Sorprenden los escasos contactos con el área italiana: una sola mención de Génova en 1468 con unos insignificantes envíos de lana, almendras o aparejos, y otro asiento para Cagliari. Más que en una falta real de contactos habría que pensar en lo incompleto de las fuentes.

$Y$ otro tanto sucede con los países musulmanes del Norte de Africa y Granada. Ni un solo dato de exportaciones hacia Berbería, y nos resulta difícil creer en la falta de contactos con estos puertos norteafricanos, que parece ser fueron uno de los pilares de la prosperidad marítimo-mercantil de Alicante en el período musulmán y durante la etapa cristiana del siglo XIII. Con el reino nazarí de Granada sólo algún envío de alimentos (queso, arroz, vino) y frutos secos a Almería.

De gran iterés es la ruta que utilizaba el puerto de Alicante como escala hacia Levante, es decir los países situados en la cuenca oriental del 
Mediterráneo (24). En 1490 se contabilizaron doce embarcaciones que se llevaban con preferencia pasas, aparejos y pequeñas cantidades de frutos secos, hierro, sosa o vino, asi como vituallas para la travesía. Algunas naves hacian escalas en Valencia o Mallorca antes de proseguir hacia Levante.

En el área atlántica, al margen de algún embarque esporádico hacia Sevilla o Portugal, era Flandes la ruta que merecía mayor atención a finales del siglo XV, hasta el punto de que el dret del general de 1940 dedica un apartado a las naves que van a Flandes, Poniente y Levante. Su rendimiento impositivo era también superior al ser productos más valiosos los intercambiados.

Se trataba de embarcaciones que hacían la ruta Mediterráneo-Atlántico, con frecuencia italianas, como las galeras florentinas o venecianas, si bien naves y carabelas son las embarcaciones más utilizadas. En otros casos cubrían la línea Levante-Flandes, como la nave de Francisco Darteycat en 1490. Los productos exportados cubrían una amplia gama, desde los aparejos y especias a las pasas y el vino, que son los dos artículos objeto de mayor demanda.

\section{d) Productos exportados}

La primera observación que surge al comparar el año 1468 con 1490 es el paso de 81 a 131 productos o variedades de los mismos, lo que supone un incremento no sólo de la cantidad sino también de la calidad, como veremos. Pero estas cifras no deben llevarnos a engaño, ya que muchos de estos artículos sólo salen de manera esporádica, particularmente las manufacturas, y su presencia hay que considerarla como testimonial, no pudiendo hablarse de un comercio de exportación diversificado. Este aparece monopolizado por unos cuantos productos, cual son los higos, pasas, frutos secos, vinos y fibras vegetales, en bruto o elaboradas. Materias primas, pues, a cambio de manufacturas. Pero veamos con un poco de detenimiento la situación real.

Los productos alimenticios y su tráfico dan vida al puerto de Alicante, situándose en cabeza las pasas y los higos. La elaboración de las pasas, blanca o negra, cuenta con una gran tradición en las comarcas litorales alicantinas, particularmente La Marina, y por Denia o Alicante se enviaban a las Baleares, Levante y, en particular, a Flandes, siendo a veces ésta la única mercancía que se cargaba en Alicante para esta región atlántica. Con todo se aprecia un descenso en los envíos entre 1468 y 1490 (de 10.289 quintales se pasa a 8.421) (25).

Los higos se exportaban en cantidades inferiores: a menudo lo hacian en forma de panes. Hay un acusado descenso entre los 2.007 quintales de 
1468 y los 365 de 1490 , y sus destinos son más variados que las pasas, prácticamente todas las rutas que salen de Alicante, puerto que actuaba como receptor de pequeñas embarcaciones que transportaban estos articulos desde aquellos lugares donde no podian atracar navios de gran porte (26).

Las bondades del vino alicantino fueron muy estimadas a fines de la Edad Media, de ahi que fuera objeto de una creciente demanda, tanto el blanco como el tinto, aunque lo habitual era denominarlo simplemente "vi». Se enviaba a Levante, Baleares, Niza, Cagliari, y sobre todo, a Flandes.

El pescado del litoral no bastaba para satisfacer las necesidades locales, sobre todo en determinadas épocas del año, por lo que había que importarlo de fuera, en particular de Andalucía y Portugal. Las especies más comunes eran la sardina (blanca, salada, arencada o normal) exportada por millares o en pipas; el congrio, la anchoa; la merluza, por docenas; en ocasiones se cita atún de “zorra» (hijada del atún) y de «bada». Todo este pescado era redistribuido hacia Castilla, y en menor medida Mallorca, Cartagena, etc. así como el aprovisionamiento de los buques.

Entre los frutos secos, de gran tradición local, tan sólo aparece la almendra, exportada en pequeñas partidas a Mallorca, Génova, Flandes, Almería o Niza.

Otros artículos destinados al consumo humano y exportados eran las especias (en especial el comino), el azúcar, aceite, queso, miel, azafrán o arroz, pero en pequeñas cantidades.

Las materias primas tienen como base las fibras vegetales, siendo el esparto, muy cultivado en toda la gobernación de Orihuela, la de mayor demanda. Lo habia de diferentes tipos: en bruto, cocido, de criba, de primera calidad (melloria), de Mallorca o «mercader», y se enviaba por millares, aunque aparece esporádicamente.

De las fibras vegetales textiles, el cáñamo es la única que merece citarse, siendo Flandes uno de los puntos receptores.

Para la industria textil se exportaban algunas partidas de alumbre grana, rubia, pastel, a Mallorca, Flandes, etc.

Entre los minerales, de los que el País Valenciano siempre ha sido deficitario, hay que citar los reenvíos de hierro hacia Castilla y alguna mención de estaño, plata o azufre, este último hacia Flandes.

Ocasionalmente salen también por vía marítima cueros, pieles de cordero y cabrito, corcho, madera, sosa, sebo y alguna partida de lanas a Mallorca o Génova.

Por último, las manufacturas, entre las que destacan las elaboradas con fibras vegetales, el esparto: son cuerdas de todo tipo y diámetro las más solicitadas (maroma, pleita, jarcias, tomizas delgadas, medianas o 
gruesas, etc.), esteras «mercaderes», alpargatas, etc. enviadas a todas las áreas con las que Alicante se relacionaba, y especialmente, Mallorca.

Hay menciones a salida de loza (Génova y Castilla), ruedas de molino (a Castilla), maderas, tornos, jabón (a Cartagena), papel en balas (a Castilla, Mallorca e Ibiza), botones de coral (a Flandes), frascas de agua, cerámica, zuecos (a Tarragona y Mallorca), baúles, algún cuchillo, pero siempre en cantidad reducida, reflejo de la debilidad artesana alicantina.

Sin embargo, hacia 1490 se produjo un importante cambio con respecto a años anteriores, al incrementarse la exportación de manufacturas de calidad y en algunos casos de lujo. Destaca la enorme variedad de tejidos, desde los simples paños («draps») a los camelotes y fustanes de diversos colores, pasando por los lienzos de París, vervins de Sicilia o damascos. Estas telas, procedentes en su mayoría de los países atlánticos del Norte de Europa, tenían su destino final en Castilla, donde la poderosa nobleza y las oligarquías locales eran su mejor cliente.

Alicante también enviaba hacia el interior de la Peninsula artículos selectos como alguna patena de plata, vidrio, hilo de Brabante y de Borgoña, rosarios de diversos colores, sin que falten los libros «d'emprempta», grandes y pequeños, reflejo del impacto y difusión que el descubrimiento de Gutenberg tenía en los albores del mundo moderno.

\section{LOS IMPUESTOS}

Todo este tráfico mercantil marítimo por el puerto de Alicante generaba una serie de impuestos, cuyo beneficiario era generalmente el monarca. Los más importantes y el estado actual de conocimientos de los mismos es el siguiente:

\section{a) El «dret de treta de les coses vedades»}

Existía una serie de productos cuya exportación del reino de Valencia se veía gravada con el citado impuesto. Hasta ahora ha sido la principal fuente para conocer la trayectoria del comercio bajomedieval valenciano, en concreto la ciudad de Valencia y en menor medida la de Castellón de la Plana (27), ignorándose el de otras localidades del País Valenciano. Sin embargo, al analizar las cuentas de la bailía de Orihuela-Alicante, en el apartado "esdeveniments en la vila $i$ e terme d'Alacant" fueron recogidas las vicisitudes de parte de este tráfico de productos prohibidos.

No es mi intención realizar un estudio pormenorizado del mismo (28), sino simplemente trazar sus líneas generales. En principio, señalar cómo las noticias más abundantes corresponden al último cuarto del siglo XIV, que debió de ser una etapa bastante activa en este tráfico, visible en el 
número de asientos y en la suma recaudada en concepto de impuesto. Pero se trata siempre de un tráfico muy reducido; en 1377, por ejemplo, sólo se contabilizan 17 asientos, y en torno a 15 en otros años, cifras meramente testimoniales si las comparamos con los dos millares de embarques que a menudo tienen lugar en el puerto de Valencia por estas fechas.

Era un comercio fundamentalmente en manos de mercaderes alicantinos y mallorquines, apareciendo también algún provenzal, barcelonés o de Villajoyosa, sin que falten los judíos. Los puntos de destino eran la ciudad de Mallorca en primer lugar, seguida de Barcelona, y en menor escala Valencia, Ibiza, Cartagena, Villajoyosa o Murcia.

Los productos que se extraían eran básicamente la pez, el sebo y el cáñamo. por este orden, hasta el punto de que en una ocasión se califica a este impuesto como "dret de treta de pega, seu e canem" (29). En cantidades más pequeñas salían algunos artículos alimenticios como trigo, cebada, harina, panizo.

Es un comercio que presenta fuertes oscilaciones,anuales en el último cuarto del siglo XIV, con sus puntos álgidos en 1390 y 1391, en los que se recaudaron 552 y 316 sueldos respectivamente, desapareciendo prácticamente sus huellas a finales de siglo y comienzos de la centuria siguiente. En 1411, por ejemplo, sólo se recaudaron 51 sueldos, indicándose que se trataba de las "coses vedades» que iban a Castilla (30). Lo que pasó con las que salian por vía marítima lo ignoramos. Lo cierto es que a finales de siglo hubo un descenso: 130 sueldos recaudados en 1489 , para remontarse a 300 en 1490 y 446 en 1491, siguiendo la tónica general de crecimiento del puerto alicantino.

b) El «dret de duana»

Ya desde su incorporación a la cristiandad los monarcas se reservaron el derecho de aduana en el puerto de Alicante, denominación que denota un claro origen musulmán. Equivalía al derecho de peaje, y en la ciudad de Orihuela se conocía como el «dret de moxerif», almojarifazgo. En 1398, Juan I, a ruegos de la villa de Alicante, ratificó la franquicia del derecho de aduana de la que gozaban todos sus habitantes, frente a las pretensiones de los regidores de Elche que querían hacérsela pagar (31). La otra noticia conservada sobre este impuesto es de 1488. Se trata de una carta de Fernando el Católico dirigida a todos los oficiales del reino en la que se hace referencia a la queja presentada en las Cortes celebradas en Orihuela por el síndico de Alicante referente al intento de cobrar el derecho de peaje en la ciudad de Valencia a pesar de haberlo abonado en Alicante, Orihuela $u$ otro lugar de "Sexona enllà". La sentencia real dispuso que peaje, aduana y almojari- 
fazgo eran todo un mismo derecho, y pagado una vez no debía ser reclamado de nuevo en Valencia, bajo pena de 3.000 florines (32).

El impuesto se arrendaba anualmente, conociendo su evolución desde 1376 a fines del siglo XV. En líneas generales se observa un crecimiento continuo durante todo el período, con tres claras etapas. La primera iría desde 1376 a 1418, y las sumas anuales percibidas por el arrendamiento eran inferiores a los mil sueldos, desde los 343 sueldos en 1376 a los 740 en 1418 , con dos baches en los años 1377 y 1412 , y en medio una década estable a fines del siglo XIV. La segunda etapa se iniciaría en 1419 , superándose los mil sueldos, aunque en años siguientes se descendiera alguna vez por debajo de esta cifra, llegando hasta 1468. La tercera y última desde 1469 a final de siglo en que se rebasan los 3.000 sueldos. En conjunto, no puede negarse que era un impuesto rentable para la hacienda regia.

$Y$ sin embargo no siempre se encontró arrendador para el mismo. Ya en 1376 tuvo que quedárselo un vecino de la villa, Bernat Escarabot, porque nadie acudió a la subasta del mismo, fenómeno que se repitió en otros años, como 1377 -precisamente el de menor recaudación, sólo 160 sueldos, 6 dineros-. A veces no interesaba el precio ofrecido en la subasta y el baile local encargaba su recaudación a un vecino. Normalmente los arrendadores eran de Alicante, sin que sepamos sus profesiones, aunque puede pensarse que algunos fueran mercaderes, como Jaume Dartes $(1418,1419)$ o Francesch Dartes $(1441,1443)$, pues un Pere Dartes, probable miembro de esta familia, está muy vinculado a las actividades comerciales de fin de siglo. En 1421 lo arrendó un moro alicantino, Alí Alfaquí, y en 1489 un portugués, Diego López. Algunos se quedaron el arriendo varios años seguidos como Juan Pidrolo entre 1439 y 1441 , ambos inclusive.

\section{c) El «dret del general»}

Organizada definitivamente a partir de principios del siglo XV la Diputació del General del Rene de València se planteó el problema de recaudar fondos, para lo cual se creó un impuesto que gravaría la entrada y salida de mercancías del reino, así como su compra y consumo en el interior. Son las llamadas "generalitats» (33).

Los productos fueron agrupados por capítulos de acuerdo con la siguiente denominación (34):

1. Capitol del tall de draps de la ciutat de Valencia e terme antich de aquella.

2. Capitol del tall de draps de toles les ciutats e viles reyals (se exceptuaba Valencia y Orihuela).

3. Capitol del tall de draps de la ciutat de Oriola. 
4. Capitol de la treta de lanes squilades o per squilar, de dels draps crus e de les filaces de la lana e de stam.

5. Capitol de la sal de tot lo regne de Valencia.

6. Capitol de la treta de la fusta nova per obrar, e del vi e de la entrada del vi strany.

7. Capitol de la treta del cayram cru o pelos de blanqueria e pelliceria crus; e de la treta dels boldrons e anyines e de totes pells lanars del regne de Valencia.

8. Capitol de la treta del arroç blanch e vermell; e de la treta de les peces e pells apparellades de pelliceria, e del argent per obrar e obrat vell, e del spart obrat e per obrar.

9. Capitol de la treta de les tintes e de la speciayria, e de les armes noves, e del peix salat e de la çenra.

10. Capitol de la treta de diverses robes e mercaderies del regne.

11. Capitol de la quincalleria.

Según Camarena Mahiques la mayoria de estos impuestos se introdujeron en 1403, comenzando a cobrarse en 1404, permaneciendo fijos desde entonces, aunque con variaciones.

Según Martínez Aloy las ropas y los tintes que se extraian del reino abonaban por el derecho de mercadería 6 dineros por libra; el arroz en cáscara 6 dineros por carga; el arroz descascarillado 12 dineros y el esparto 2 dineros (35).

Estos derechos fueron ampliados en las Cortes de 1428 para poder hacer frente al fuerte subsidio de 112.000 florines afrecido a la Corona, fijándose los siguientes derechos:

\section{Derechos de exportación}

Ropas y telas, 9 dineros por libra.

Lanas cargadas en Tortosa por los habitantes del reino, 6 dineros. Arroz sin cáscara, 2 sueldos por carga.

Arroz con cáscara, 1 sueldo por carga.

Esparto, 1 sueldo por libra.

Reexportación de telas extranjeras, 6 dineros por libra.

Telas de algodón, lino, cáñamo, baldeses, papel, mercería y quincalleria, 6 dineros por libra.

Pellejería, 10 dineros por libra.

Madera nueva, 12 dineros por libra.

Seda en rama, 6 dineros por libra.

Nuevos impuestos se añadieron en las Cortes de 1446. 


\section{Derechos de exportación}

Esclavos, 10 sueldos por cabeza.

Bestias mayores, 4 dineros por libra de su valor.

Oro y piedras preciosas, 6 dineros por libra.

Plata labrada, 6 dineros por libra.

Moneda, 3 dineros por libra.

Libros científicos y literarios, 18 dineros por libra.

Madera sin labrar, 2 sueldos.

\section{Derechos de importación}

Esclavos entrados en el reino, 10 sueldos por cabeza.

\section{Derechos de rescate}

Esclavos rescatados que salen del reino, 2 sueldos por libra del importe del rescate.

Derechos por transición de la propiedad

Esclavos, 4 dineros por libra de su precio, pagaderos por mitad adquiriente y transmisor.

No pagan los esclavos, animales, joyas y dinero de las gentes del reino, cuando sea para uso propio.

El dret del general era el que producia mayores ingresos, recaudándose en 1649 la suma de 516 libras, 4 sueldos y 11 dineros, que deducidos los gastos de los colectores, 37 libras y 4 sueldos, quedó en 477 libras, 10 sueldos, 11 dineros (36).

Este impuesto parece que se mantuvo bastante estable a fines del siglo $X V$, y en 1490 los ingresos fueron de 551 libras, 3 sueldos, 1 dinero, y de 509 libras, 9 sueldos, deducidos gastos.

d) El «dret del moll»

Las escasas noticias que hoy tenemos sobre este impuesto proceden todas de finales del cuatrocientos, sin que sepamos de qué mercancias gravaba ni en qué cuantía, aunque sí conocemos el destino de este impuesto. En una carta de Fernando el Católico a las autoridades alicantinas se hace alusión a un privilegio de la villa de Alicante para poder imponer sisas en la misma y su término, y a la pretensión de aplicarlo al 
impuesto "vulgum dictum de entrada e exida", que se exigia de todos los productos a razón de 3 dineros por libra. Se les recuerda que dicho impuesto sólo podía ser exigido por el monarca, al ser una regalía. A este problema entre el fisco y los jurados alicantinos se añadió el referente al «iure vulgo dicto del moll». La sentencia dada por el baile autorizó a las autoridades a imponer sisas y otros tributos, aunque el de entrada y salida lo debía recaudar el baile local en nombre del soberano.

Sobre el «dret del moll» se mostraron dos privilegios dados por Juan II. uno fechado el 8 de diciembre en Barcelona - no se indica el año-. cuyo original había desaparecido. si bien se conservaban copias en el Archivo Real de Valencia, según el cual se concedia la cuarta parte del citado derecho para la conservación de la fábrica y obra del castillo de Alicante. El otro privilegio se dio el 18 de marzo de 1476 en Zaragoza y destinaba todo el producto del derecho para la conservación del muelle, aunque la cuarta parte seria recibida por el baile de la villa y destinada al castillo.

Las autoridades de Alicante interpusieron recurso contra esta decisión a través de sus enviados Jaume Pasqual y Joan Jorro, quienes solicitaron al monarca que consultara a un abogado experto. Don Fernando, con el fin de no prolongar la situación en pleitos, dio la siguiente sentencia: el derecho del muelle no seria exigido por él y sus sucesores, haciendo donación del mismo a la villa. Se suspendió cualquier pena civil o criminal pendiente con el fisco y se autorizó a los regidores a imponer sisas o impuestos sobre las mercancias similares a los de la ciudad de Valencia, pudiendo destinarlo a las necesidades del municipio. Del arriendo del citado derecho, una vez deducidos los censales del muelle y sus gastos ordinarios, se harian cuatro partes: tres para su conservación y reparación, y en sus puertas habria una bombarda con la munición que se considerase necesaria, amortizándose con dinero procedente de este derecho. De estas tres partes los jurados podrían gastar lo que creyeran oportuno en beneficio de la villa. El puerto pasaba a ser una fuente más de ingresos para las arcas municipales (37).

Normalizada la situación jurídica, tenemos noticias del arrendamiento del derecho del muelle desde 1491 a 1501, que ofrece el siguiente cuadro:

\begin{tabular}{lcccc} 
& 1491 & 1492 & 1493 & 1494 \\
\cline { 2 - 5 } Arrendador & $\begin{array}{c}\text { Cristofol } \\
\text { Marti }\end{array}$ & $\begin{array}{c}\text { Jaume } \\
\text { Danton }\end{array}$ & $\begin{array}{c}\text { Jaume } \\
\text { Danton }\end{array}$ & $\begin{array}{c}\text { Tomás } \\
\text { Martí }\end{array}$ \\
\hline $\begin{array}{c}\text { Suma percibida } \\
\text { (sueldos) }\end{array}$ & 1.720 & 760 & 1.860 & 2.000 \\
\hline $\begin{array}{l}\text { Beneficio para el } \\
\text { rey y castillo }\end{array}$ & $195 \mathrm{~s}, 9 \mathrm{dr}$. & $206 \mathrm{s.}$ & $268 \mathrm{~s}, 9 \mathrm{dr} .268 \mathrm{~s}, 9 \mathrm{dr}$. \\
\hline
\end{tabular}




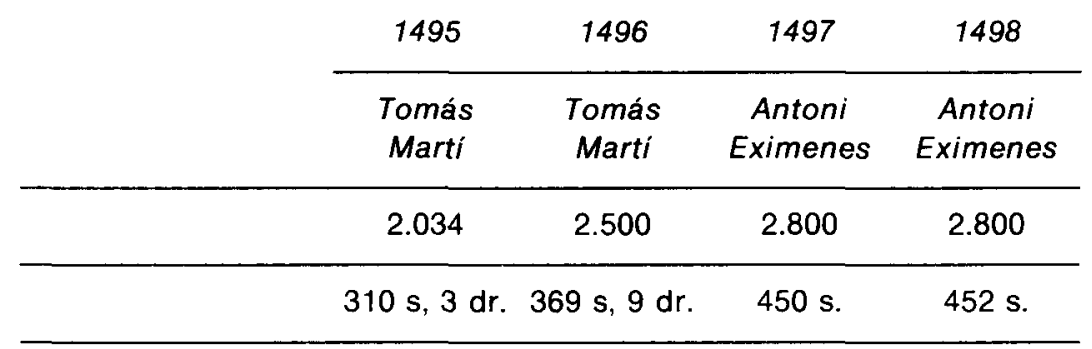

Desde 1497 el arriendo se trasladó desde el día de San Miguel al día 1 de enero por disposición del baile. A lo largo de estos años se observa un lento, pero continuado crecimiento del impuesto, del que anualmente se deducía una suma destinada al pago de censales (unas 39 libras) y salarios. En la partida de gastos se incluía los realizados por la compra de bombardas, pólvora, diversos materiales para obras, salarios por éstas, correos, etc.

Señalemos para terminar que en 1500 se arrendó al ya citado Antoni Eximenes por 2.600 sueldos, descenso que se explica por el peligro de peste, que retrajo la presencia de algunas naves a la rada alicantina. Sabemos que 5 naves y 1 carabela portuguesa, 1 galera de Niza, 2 naves que venían de Roma, así como otras portuguesas fueron ordenadas salir del puerto por los oficiales reales, no cobrándose el mollaje, ya que no había capítulos previstos para los casos de emergencia (38). En 1501 se gastaron 14 sueldos para la bandera del morbo (39). 


\section{NOTAS}

(1) E. GIMENEZ LOPEZ, Alicante en el siglo XVIII. Economia de una ciudad portuaria en el antiguo régimen, Valencia, 1981.

(2) V. MARTINEZ MORELLA, El puerto internacional de Alicante durante la Edad Media, Alicante, 1959. Este trabajo se presentó como ponencia al «Congreso Histórico de Portugal Medievo", en Braga, 1959.

(3) J. TORRES FONTES, "Alicante y su puerto en la época de Alfonso X el Sabio y Jaime l", en I.P.E.A., 19 (1978), p. 11-24.

(4) MARTINEZ MORELLA, op. cit., p. 10, y J. TORRES FONTES, op. cit., p. 12.

(5) J. TORRES FONTES, op. cit., p. 19-20.13 y sig.

(6) J. TORRES FONTES, op. cit., p. 19-20.

(7) J. M. DEL ESTAL, Singular relevancia del "castrum d'Alacant " a tenor de una provisión real inédita de Pedro $N$ de Aragón, Item V (1981), p. 51-63.

(8) V. MARTINEZ MORELLA, op. cit., p. 12.

(9) Archivo Municipal de Alicante (en lo sucesivo, A.M.A.), armario 1, libro 2, fol. $67 \mathrm{~V}$.

(10) A.M.A., armario 1, libro 7, fol. 356.

(11) GARCIA MERCADAL, Viajes de extranjeros por España y Portugal, Madrid, 1952, p. 344-345.

(12) J. LOPEZ GOMEZ, El puerto de Alicante. Estudios Geográficos, XVI, 60 (1955), p. 511-584, en concreto p. 518.

(13) A.M.A., armario 5, libro 818, fol. 5 r. tes.

(14) Archivo del Reino de Valencia (en adelante, A.R.V.), Maestre Racional 4543, y siguien-

(15) A.R.V., Generalidad 2109.

(16) A.M.A., armario 5, libro 18.

(17) A.R.V., Generalidad 2109, año 1490 , sin foliar.

(18) Cl. CARRERE, Barcelona, centre economique 1380-1462, París-La Haya, 1967, p. 548-549.

(19) E. BENITO RUANO, "Avisos y negocios del mercader Pero de Monsalve", en Boletín de la Real Academia de la Historia, CLXIX, fasc. 1-2 (Madrid, 1972), p. 136-169.

(20) E. SALVADOR, La economia valenciana en el siglo XVI (comercio de importación), Valencia, 1972.

(21) A.R.V., Generalidad 2109, año 1468, sin fol.

(22) Cl. CARRERE, op. cit., p. 548.

(23) A.R.V., Generalidad 2109, año 1468, sin fol.

(24) F. BRAUDEL, EI Mediterráneo y el mundo mediterráneo en la época de Felipe $1 /, 2 .^{a}$ ed. española (1976), I, p. 160 y 174, alude a Levante.

(25) El quintal equivale a 41,5 quilogramos.

(26) E. GIMENEZ, op. cit., p. 382.

(27) J. HINOJOSA MONTALVO, Coses vedades en 1404, Valencia, 1972; Valencia y el comercio de exportación durante la primera década del siglo XV (Coses vedades), tesis doctoral inédita, Valencia, 1972; R. FERRER NAVARRO, La exportación valenciana en el siglo XIV, Zaragoza, 1977; Aportación al comercio valenciano en el año 1393, en Estudios de Edad 
Media de la Corona de Aragón, IX, Zaragoza, 1973, p. 161-184; P. LOPEZ ELUM, Coses vedades en Castellón de la Plana, 1412, 1421, Valencia, 1973, entre otros trabajos publicados e inéditos sobre el tema.

(28) M. L. CABANES CATALA, EI puerto de Alicante a fines del siglo XIV, en prensa.

(29) A.R.V., Maestre Racional, 4543, fol. 34 v.

(30) A.R.V., Maestre Racional, 4546, fol. 2 r.

(31) A.M.A., armario 1, libro 2, fol. 66 v-67 r.

(32) A.M.A., armario 1, libro 9, fol. $30 \mathrm{r}$.

(33) J. CAMARENA MAHIQUES, «Función económica del General del Regne de Valencia en el siglo XV», en Anuario de Historia del Derecho Español, XXV (1955), p. 529-542.

(34) J. CAMARENA MAHIQUES, op. cit., p. 531-532.

(35) J. MARTINEZ ALOY, La Diputación de la Generalidad del reino de Valencia, Valencia, 1930 , p. 230.

(36) A.R.V., Generalidad 2109, fol. 28 v.

(37) A.M.A., armario 1, libro 28, fol. 28; pergaminos N. ${ }^{\circ} 31$. Lo reproduce V. MARTINEZ MORELLA, Privilegios y provisiones de Fernando el Católico a Alicante, Alicante, 1951, p. 19-24.

(38) A.M.A., armario 5, libro 18 , fol. $42 \mathrm{v}$.

(39) A.M.A., armario 5 , libro 18, fol. $50 \mathrm{r}$. 